\title{
Role of heat shock proteins in the pathogenesis of cystic fibrosis arthritis
}

\author{
M R R Al-Shamma, C McSharry, Kirsten McLeod, E A B McCruden, B H R Stack
}

\begin{abstract}
Background-Arthritis is a well recognised complication of cystic fibrosis. The cause of this arthritis is not yet clear but it is likely to be an immunological reaction to one of the many bacterial antigens to which the lungs are exposed. One such group, the heat shock proteins (hsp), was investigated. These are immunodominant antigens of a wide variety of infectious microorganisms and have varying amino acid chain sequences, some of which are similar to those found in human tissues.

Methods - Antibodies to human hsp 27 and hsp 90 in the serum of patients with cystic fibrosis, with and without arthritis, and in normal age and sex matched healthy controls were measured. The severity of the cystic fibrosis was assessed by lung function tests and chest radiographs. The nature of the organisms colonising the lungs was determined by bacteriological examination of sputum.
\end{abstract}

Results - Higher mean titres of serum IgG anti-human hsp 27 and hsp 90 antibodies were found in 50 patients with cystic fibrosis than in healthy controls (hsp 27, 0.25 (95\% CI 0.19 to 0.33$)$ versus 0.05 (95\% CI 0.04 to 0.07$)$; hsp $90,0.27(95 \%$ CI 0.22 to $0.32)$ versus $0.11(95 \%$ CI 0.08 to 0.14$)$ ). These antibodies were higher in patients in whom the lungs were colonised with Pseudomonas aeruginosa than in those without infection (hsp 27, 0.41 (95\% CI 0.17 to 0.63$)$ versus $0.18(95 \%$ CI 0.10 to $0.27)$; hsp 90, 0.37 (95\% CI 0.18 to 0.57 ) versus $0.22(95 \%$ CI 0.16 to 0.29$))$. The eight patients with cystic fibrosis with arthritis had higher anti-hsp 27 antibodies (0.48 (95\% CI 0.13 to 0.92$)$ ) than the 42 patients without arthritis $(0.22$ (95\% CI 0.17 to 0.30 )).

Conclusions - These findings suggest that the arthritis associated with cystic fibrosis, despite being seronegative for rheumatoid factor, was associated with more severe lung disease and with a greater inflammatory response to heat shock proteins.

(Thorax 1997;52:1056-1059)

Keywords: cystic fibrosis, heat shock protein.

Correspondence to:

Dr M R R Al-Shamma,

Department of Medicine,

Vale of Leven Hospital,

Dumbartonshire G83, UK

Received 6 February 1996

Returned to authors

9 May 1997

Revised version received

22 August 1997

Accepted for publication

22 August 1997 organisms including bacteria, mycobacteria, protozoa, and helminths. The major mammalian hsp have estimated molecular weights of $110,90,73,72,55,47,28,27$, and $8 \mathrm{kDa}$. Hsp 90 is the most abundant of the stress proteins and has a rod-like structure that binds and regulates many important proteins, including actin-myocin filaments. The small stress proteins are essential for chromosomal organisation and they are also important in ATP dependent proteolytic degradation of unstable cellular proteins.

Heat shock proteins may provide a link between infectious diseases and autoimmunity whereby immune reactivity induced by bacterial hsp antigens reacts against similar antigenic determinants on mammalian tissues. Patients with reactive arthritis have increased synovial $\mathrm{T}$ cell reactivity to Gram negative bacteria $^{1}$ and antibodies to exogenous stress proteins were detected in the serum and synovial fluid of patients with juvenile chronic arthritis. ${ }^{2}$ High levels of serum IgG anti-human hsp 60 antibodies were documented recently in a group of patients with cystic fibrosis, ${ }^{3}$ and hsp 60 has been reported to have sequence homology with a wide range of tissue-specific proteins including the auto-antigens of rheumatoid arthritis, scleroderma, and glomerulonephritis. ${ }^{4}$ Arthritis is common in patients with cystic fibrosis with a reported frequency of $8.5-9 \%$, but the pathogenesis is unknown. ${ }^{56}$ One explanation for the development of arthritis may be that it is secondary to the production of antibodies to bacterial hsp antigens associated with chronic lung infections. The aim of this study was to establish whether anti-human hsp 27 and hsp 90 antibodies are present in patients with cystic fibrosis and to determine whether these antibodies are associated with arthritis.

\section{Methods}

SUBJECTS

Fifty patients ( 28 men) of mean age 21 years (range 16-34) attending the West of Scotland Adult Cystic Fibrosis Centre were studied. Cystic fibrosis was diagnosed on clinical grounds and positive sweat tests. Patients were selected randomly; all were in remission at the time of the study and had had no acute exacerbations for at least four weeks prior to their enrolment. All patients completed a questionnaire about past or present symptoms of arthritis. Those who had symptoms underwent full rheumatological evaluation. Forced expiratory volume in one second $\left(\mathrm{FEV}_{1}\right)$ was calculated as the highest value in a series of 
Table 1 Age and sex distribution of patients with cystic fibrosis with and without arthritis and normal controls

\begin{tabular}{llll}
\hline & $\begin{array}{l}\text { Arthritis } \\
\text { patients } \\
(n=8)\end{array}$ & $\begin{array}{l}\text { Non-arthritis } \\
\text { patients } \\
(n=42)\end{array}$ & $\begin{array}{l}\text { Controls } \\
(n=46)\end{array}$ \\
\hline Mean (range) age (years) & $19(16-24)$ & $21(16-34)$ & $22(16-34)$ \\
Sex (M:F) & $4: 4$ & $22: 20$ & $23: 23$ \\
FEV 1 (\%) predicted) & $39^{*}$ & 67 & NA \\
Chest radiograph (Northern score) & $5.5^{*}$ & 3.5 & NA \\
P aeruginosa colonisation & $6^{*}$ & 14 & NA \\
\hline FEV & forced expiratory volume in one second; NA=not applicable. & \\
${ }^{*} \mathrm{p}<0.05$. & &
\end{tabular}

three forced vital capacity manoeuvres using a dry wedge Vitalograph spirometer. Sputum culture and chest radiography were performed in all patients and the Northern score calculated. Forty six age and sex matched healthy workers interviewed during a factory survey of occupational asthma served as controls. ${ }^{7}$ They had no allergic sensitisation and were not taking any significant medication.

HEAT SHOCK PROTEIN ANTIBODY ASSAYS

Serum IgG anti-human hsp 27 and hsp 90 were measured in venous blood using recombinant proteins (Bioquote Ltd, York, UK proteins approximately $90 \%$ pure by SDS-PAGE). Serum antibody to these was measured by enzyme immunoassay (EIA). Briefly, each hsp was incubated at $10 \mu \mathrm{g} / \mathrm{ml}$ in bicarbonate coupling buffer $\mathrm{pH} 9.5,100 \mathrm{ml}$ per well in microtitre EIA plates (Dynatech Ltd), overnight at $4^{\circ} \mathrm{C}$. The plates were washed three times by shaking out and immersion into wash buffer (PBS $0.02 \mathrm{M}, \mathrm{pH} 7.4$, containing $0.05 \%$ Tween-20). Patients and control serum samples were diluted 1 in 50 with wash buffer and added at $100 \mu \mathrm{l}$ per well. After incubation for two hours the plates were washed as before. Any bound IgG antibody was detected by incubating with alkaline phosphatase conjugated anti-human IgG (isotype specific, Sigma UK Ltd) diluted 1 in 5000 with wash buffer at $100 \mu \mathrm{l}$ per well for two hours at room temperature. After washing as before the enzyme activity of the bound conjugate was measured by incubating with $\mathrm{P}$ nitrophenyl phosphate (Sigma UK Ltd), $100 \mu \mathrm{l}$ per well, at $1 \mathrm{mg}$ per $\mathrm{ml}$ in $10 \%$ diethanolamine in water, $\mathrm{pH} 10.5$. The enzyme activity is seen as a change from colourless substrate to a yellow product.

After 30 minutes the reaction was stopped with $3 \mathrm{~N} \mathrm{NaOH}$ and the colour measured by spectrophotometry (Dynatech MR 600) at $405 \mathrm{~nm}$. The absorbance was proportional to the serum antibody level if all other agents were in excess. The specificity of the EIA was confirmed by the reproducibility of the test measurements on several occasions (coefficient of variation $(\mathrm{CV})<15 \%)$, by the dose responsiveness of the optical density measurements with increasing dilution of a high titre serum, and by specific inhibition of the antibody activity by incubating test serum with excess free hsp overnight prior to assay. Total serum IgG levels were measured by nephelometry (Behring UK Ltd).
ANALYSIS OF DATA

All data were analysed using Minitab software (Minitab Inc). As the titres of anti-hsp antibodies were not normally distributed, comparisons between groups were made using the Student's paired $t$ test on log-transformed values, $\mathrm{p}$ values of $<0.05$ being considered significant. The association between serum IgG anti-human hsp 27 and hsp 90 antibody titres and the presence of persistent colonisation with Pseudomonas aeruginosa was studied by analysis of variance.

\section{Results}

Details of the patients with $(n=8)$ and without arthritis $(n=42)$ and the controls $(n=46)$ are given in table 1 . The frequency of persistent colonisation with Pseudomonas aeruginosa was significantly higher in the arthritis group. This group also had more severe pulmonary disease as indicated by a lower mean $\mathrm{FEV}_{1}$ and higher chest radiographic Northern score. All patients were negative for rheumatoid factor but two were positive for antinuclear factor, one in the arthritis group and the other in the non-arthritis group.

The geometric mean (95\% confidence interval (CI)) serum IgG anti-human hsp 27 antibody level was significantly higher in patients with cystic fibrosis than in controls (0.25 (95\% CI 0.19 to 0.33 ) and 0.05 (95\% CI 0.04 to 0.07), respectively; $\mathrm{p}<0.0001)$. Similarly, the geometric mean serum IgG antihuman hsp 90 antibody level was significantly higher in patients with cystic fibrosis than in controls $(0.27$ (95\% CI 0.22 to 0.32$)$ and 0.11 (95\% CI 0.08 to 0.14$)$, respectively; $\mathrm{p}<0.0001)$

The comparison of hsp antibody titres between arthritic and non-arthritic cystic fibrosis patients and controls is shown in fig 1 . In the patients with cystic fibrosis the geometric mean (95\% CI) serum IgG anti-human hsp 27 antibody level was significantly higher in the arthritis group than in the non-arthritis group $(0.48$ (95\% CI 0.13 to 0.92 ) and 0.22 (95\% CI 0.17 to 0.30 ), respectively; $\mathrm{p}<0.01)$. The geometric mean (95\% CI) serum anti-human hsp 90 antibody level was also higher in the arthritis group than in the non-arthritis group $(0.37$ (95\% CI 0.18 to 0.65$)$ and 0.25 (95\% CI 0.19 to 0.31 ), respectively) but this difference was not statistically significant. There were significantly higher titres of antibody to both hsp 27 and 90 in both arthritic and non-arthritic patients with cystic fibrosis compared with controls.

The mean (SE) total serum IgG level (g/l) was significantly higher in the patients with arthritis than in those without arthritis (22.2 (2.3) and 13.9 (1.7), respectively; $\mathrm{p}<0.001$ ).

A comparison of the hsp antibody titres between the cystic fibrosis patients with and without colonisation with $P$ aeruginosa is shown in fig 2. The geometric mean (95\% CI) serum level of both anti-human hsp 27 and hsp 90 was significantly higher in those patients with persistent $P$ aeruginosa infection (hsp 27: 0.41 ( $95 \%$ CI 0.17 to 0.63 ) and 0.18 (95\% CI 0.10 

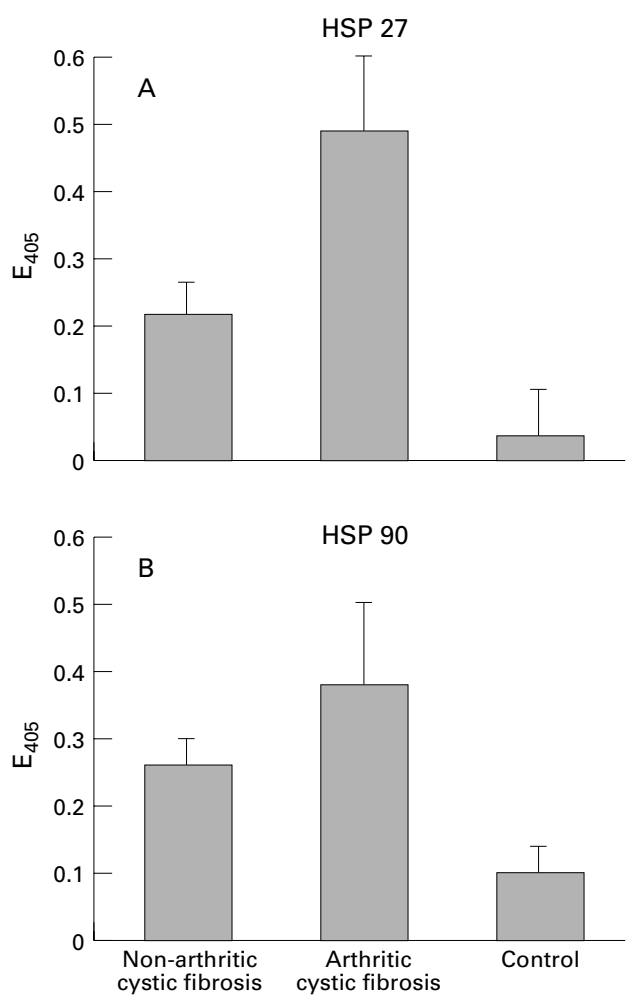

Figure 1 Geometric mean (SE) serum IgG antibody titres measured as arbitrary optical density units $\left(E_{405}\right.$ against (A) heat shock protein (hsp) 27 and (B) hsp 90 in non-arthritic and arthritic patients with cystic fibrosis and healthy controls.
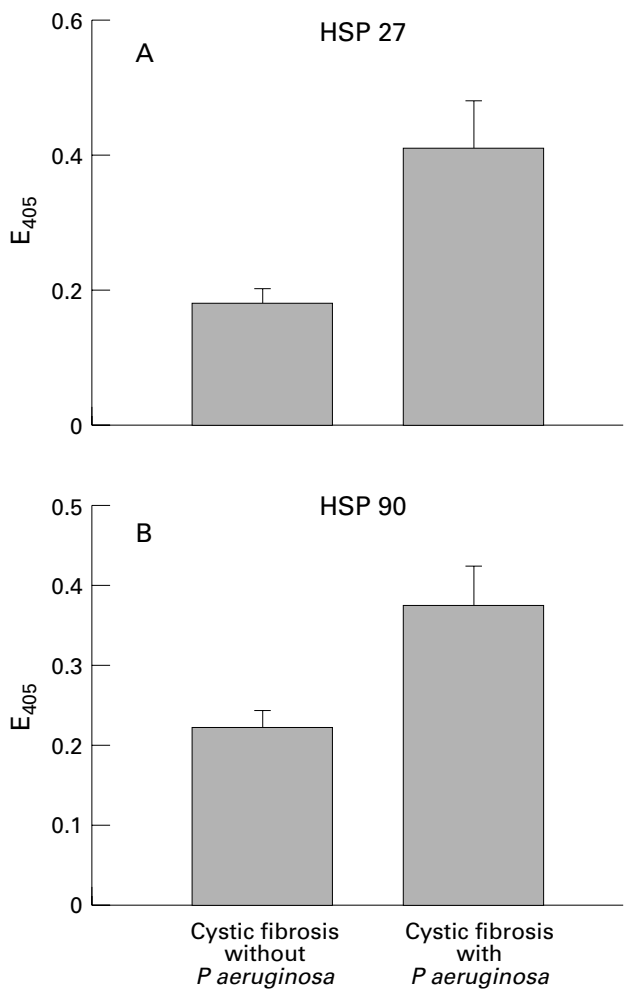

Figure 2 Geometric mean (SE) serum IgG antibody titres measured as arbitrary optical density units $\left(E_{405}\right)$ against (A) heat shock protein (hsp) 27 and (B) hsp 90 in patients with cystic fibrosis, without and with persistent colonisation with Pseudomonas aeruginosa. to 0.27 ), respectively, $\mathrm{p}<0.01$; hsp $90: 0.37$ (95\% CI 0.18 to 0.57$)$ and 0.22 (95\% CI 0.16 to 0.29 ), respectively, $\mathrm{p}<0.05)$. By analysis of variance a significant association was observed between colonisation with Pseudomonas and anti-hsp $27 \quad(\mathrm{p}<0.005)$ and anti-hsp 90 $(\mathrm{p}<0.02)$ antibody titres.

\section{Discussion}

Patients with cystic fibrosis were found to have significantly higher levels of serum IgG antibodies to human hsp 27 and 90 than healthy controls. This observation is in keeping with a recent report that patients with cystic fibrosis had high levels of IgG anti-human hsp $60 .^{3} \mathrm{It}$ is likely that the antigenic stimulus for these responses comes from the microorganisms causing the chronic chest infections including Haemophilus influenzae, Staphylococcus aureus, Pseudomonas aeruginosa and Burkholderia cepacia which are common among patients with cystic fibrosis. In the present study we found a significant association between Pseudomonas infection and antibodies to hsp 27 and 90. In addition to any local inflammatory response that these antibodies may cause in the lung, they can bind to hsp which are spontaneously shed or selectively released by organisms under stressful conditions, leading to immune complex formation. Circulating immune complex activity is commonly reported in cystic fibrosis and this may be of broader clinical significance - for example, complexes with bacterial antigens are implicated in the pathogenesis of arthritis. ${ }^{8-13}$ Moreover, antibodies to microbial stress proteins, including antibodies to mycobacterial hsp 60 and hsp 70, have been found in patients with rheumatoid arthritis and other autoimmune diseases. ${ }^{1213}$ The present findings also demonstrate an association between arthritis in patients with cystic fibrosis and high levels of serum IgG hsp 27 antibodies suggested a causal relationship which requires further attention.

In conclusion, we have established that cystic fibrosis arthritis is significantly associated with several parameters including more severe lung disease, higher frequency of persistent colonisation with $P$ aeruginosa, higher serum IgG level, and a higher level of IgG anti-human hsp 27 antibody. These findings indicate a greater inflammatory response in the patients with arthritis. It can also be concluded that the presence of IgG anti-human hsp 27 and 90 antibodies reflect in vivo exposure to the bacterial and/or human hsp. However, because of the high degree of homology in the amino acid sequences of the human and the bacterial hsp, it cannot be concluded which induced these antibodies, but as a working hypothesis it may be that the arthritis is curable by treating the lung infections.

1 Lamb JR, Young DB. T cell recognition of stress proteins A link between infections and autoimmune diseases. $M o$ Biol Med 1990;58:203-8.

2 Danieli MG, Markovits D, Gabrielli A, Corvetta A, Giorgie PL, Van Der Zee R, et al. Juvenile rheumatoid arthritis patients manifest immune reactivity to mycobacteria $65 \mathrm{kD}$ heat shock protein to its $180-188$ peptiles and to a partially homologous peptide of the proteoglycan link protein. Clin Immunol Immunopathol 1992;64:121-8. 
3 Graeff-Meeder ER, Rijkers GD, Voorhorst-Ogink MM, Kuis W, Van Der Zee R, Eden Van Zegers BJM. Antibodies to human hsp 60 in patients with juvenile chronic arthritis, diabetes mellitus, and cystic fibrosis. Int Paediatr 1993; 33:424-8.

4 Jones DB, Coulson AFW, Duff GW. Sequence homologies between hsp 60 and autoantigens. Immunol Today 1993; 13:115-8.

5 Bourke SJ, Rooney M, Fitzgerald M, Bresnihan B. Episodic arthropathy in adult cystic fibrosis. $Q \mathcal{F} \mathrm{Med} 1987 ; 64$ : 654-9.

6 Penketh A, Wise A, Mearns M, Hodson M, Batten J. Cystic fibrosis in adolescents and adults. Thorax 1987;42:526-32.

7 Douglas J, McSharry C, Blaikie L, Morrow T, Miles S, Franklin D. Occupational asthma caused by automated salmon processing. Lancet 1995;346:737-40.

8 Cantazzaro FJ, Stenson CA, Morris AJ, Chamowitz R, Rammelkamp CH, Stolzer BL, et al. Role of the streptococcus in the pathogenesis of rheumatic fever. Am f Med 1954;17:149.
9 Van den Broek MF, van de Putte LBA, van den Berg WB. Crohn's disease associated with arthritis: a possible role for gut bacteria in the pathogenesis of arthritis. Arthritis Rheum 1988;31:1077.

10 Hanglow AC, Welsh CJR, Conn P, Pitts JM, Rampling A, Coombs RRA. Experimental joint lesions in rabbits after intravenous injections of killed bacteria. Ann Rheum Dis 1986;45:50.

11 Hill JL, Yu DTY. Development of an experimental model for reactive arthritis induced by Yersinia enterocolitica infection reactive arthritis induced by Yersinia enterocolitica infection.
Infect Immun 1987;55:721.

12 Tsoulfa G, Rook GA, Bahr GM, Sattar MA, Behbehani K, Young DB, et al. Elevated IgG antibody levels to the mycobacterial $65-\mathrm{kDa}$ heat shock protein are chracteristic of patients with rheumatoid arthritis. Scand $\mathcal{F}$ Immuno 1989;30:519-27.

13 McLean L, Winrow V, Blake D. Role of immunity to mycobacterial stress proteins in rheumatoid arthritis. $\mathcal{F}$ Exp Pathol 1990;71:295-303. 